\title{
Intramolecular Radical Cyclization of Vinyl, Aryl and Alkyl Halides Using Catalytic Amount of Bis-tri-n-butyltin Oxide/Sodium Boro- hydride: A Novel Entry to Functionalized Carbocycles
}

Tarur Konikkaledom Dinesh

Namasivayam Palani*

Sengottuvelan Balasubramanian*

Synlett 2015, 26, 1055.

The compound numbers in footnote $c$ and $d$ of Table 1 are incorrect. Compound $\mathbf{1 4}$ should be $\mathbf{7 a}$ and compound $\mathbf{1 6}$ should be 8a. The editorial office apologizes for this mistake. 